
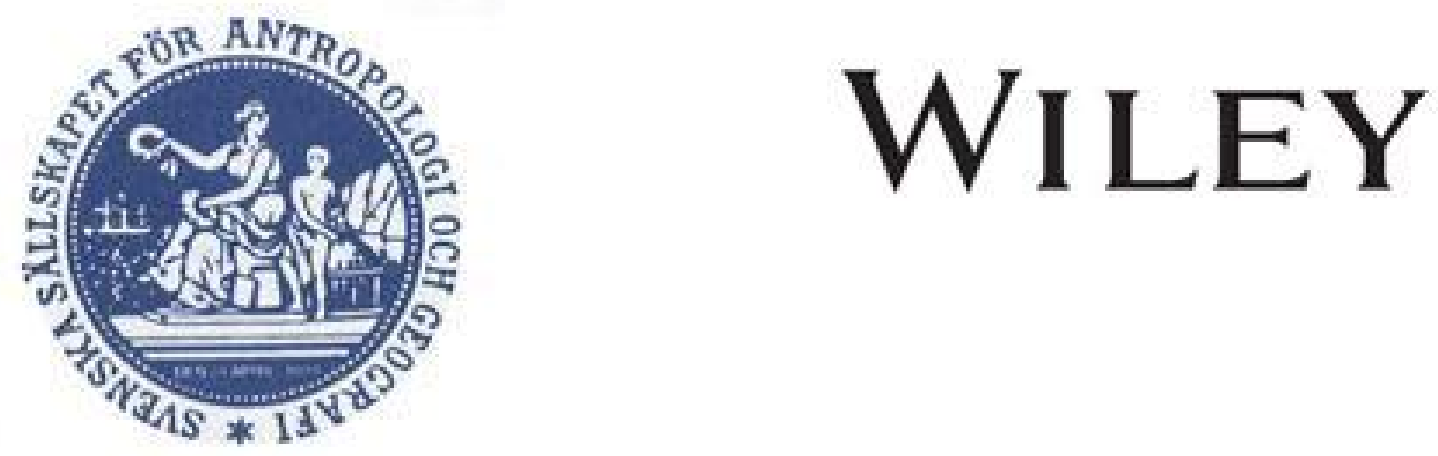

Notes on the Climatic Variations Concluded from the Dates of the First Complete Freezing of Lake Suwa in Japan

Author(s): S. Fujiwhara

Source: Geografiska Annaler, Vol. 3 (1921), pp. 358-361

Published by: Wiley on behalf of Swedish Society for Anthropology and Geography

Stable URL: http://www.jstor.org/stable/519448

Accessed: 27-06-2016 03:49 UTC

Your use of the JSTOR archive indicates your acceptance of the Terms \& Conditions of Use, available at

http://about.jstor.org/terms

JSTOR is a not-for-profit service that helps scholars, researchers, and students discover, use, and build upon a wide range of content in a trusted digital archive. We use information technology and tools to increase productivity and facilitate new forms of scholarship. For more information about JSTOR, please contact support@jstor.org.

Swedish Society for Anthropology and Geography, Wiley are collaborating with JSTOR to digitize, preserve and extend access to Geografiska Annaler 


\title{
NOTES ON THE CLIMATIC VARIATIONS CONCLUDED FROM THE DATES OF THE FIRST COMPLETE FREEZING OF LAKE SUWA IN JAPAN.
}

\author{
BI S. FUFIWHARA, Tokio.
}

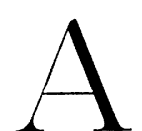

$\mathrm{S}$ is obvious, freezing of a lake takes place as the result of accumulated cold during the preceding weeks, Hence, as the measure of the general climatic feature of successive winters in the surrounding district, the period of the first complete freezing of the lake surface is more preferable to those rather accidental periods of the first ice, frost or of the first descent of thermometer below the freezing point.

There is a nearly continuous record of the dates of the first complete freezing of the surface of Lake Suwa, ${ }^{\mathrm{I}}\left(\mathrm{r} 35^{\circ} \mathrm{E}, 36^{\circ} \mathrm{N}\right)$ in Japan, during the periods, I $444-1872$ and $1893-19$ I 2 . A few years ago, the present author ${ }^{2}$ noticed the possible relation between the freezing of the lake and the latitude variation in view of the nearly coincidence of the periods and phases of both the phenomena. As far as Fig. I is concerned, the dates of the first complete freezing made fractuation with two periods, one being six or seven years and the other nearly the half of it. Freezing occurred very late in the warm winters of 1896 , 1903 , and I910, and happened rather late in 1900 and 1906 . Freezing took place very early in 1898 and 1904 , while it occurred rather early in 1902 and 1908.

Chandlar's period of the latitude variation is 14 months, and it makes out a seven years period, when combined with the period of the annual revolution of the earth round the sun. In an actual case, however, the interval of the recurring of the same phase is not strictly seven years but is sometimes six years.

1 The lake has nearly circular form, with a diameter of nearly $3 \mathrm{~km}$ and a depth of $8 \mathrm{~m}$. The temperature of the water in the lake becomes as high as $25^{\circ} \mathrm{C}$. in summer and sinks to $0^{\circ}-4^{\circ} \mathrm{C}$. in winter. Nearly every winter the surface of the lake is covered with ice and affords a good skating rink to the sporting people of lokyo. After two or three days of the first complete freezing of the surface, a big characteristic fissure of ice, called Miwatari», is produced and from its position, shape, and direction, people have been accustomed to judge the climate of the approaching summer. In this respect the state of ice was reported to the government every year since I444. The records of ice have been kept at the temple of Suwa and also at the Jaturugi shrine in this district.

2 S. Fujiwhara, on the same subject, Journal of Meteorological Society of Japan Y. 3I, p. 400. 
The difference between the azimuth of Lake Suwa and that of the position of the earth's axis at the north pole at the beginning of January is plotted in Fig. I. It made fractuation with a period of 6 or 7 years, and the years of the smallest difference of azimuths nearly coincides with the years in which the very late freezing of the lake occurred, having a little discrepancy in the year $1896 .{ }^{\mathrm{I}}$ In the latitude variation hewever, there is no short periodic variation, and hence concordance is wanted in the lower half of Fig. I.

Professor Bigelow ${ }^{2}$ has found the remarkable climatic cycles with such a short period and attributed it to the influence of the tertiary harmonic variation of

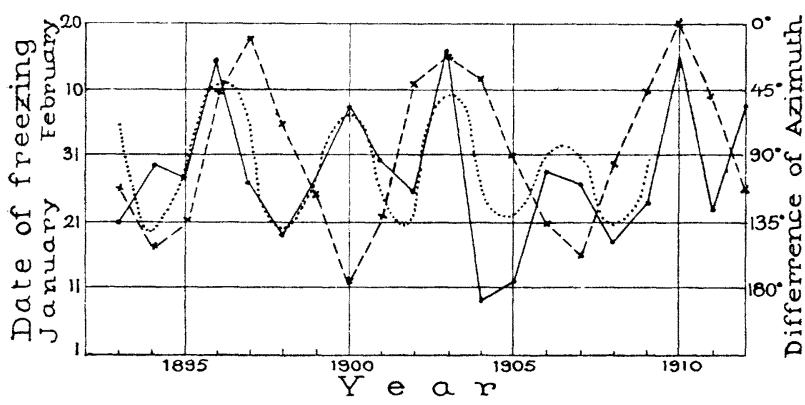

Fig. I. solar activity with a period of 3,7 years. In Fig. 1 we can see that this tertiary activity given by Professor Bigelow keeps very remarkable coincidence in phase and period with the variation of the date of freezing. If we put a little more weight to the solar in fluence and a little less to that of the latitude variation, and add those two weighted influences together, then there is a possibility to explain the climatic variation, which reveals itself in the course of the freezing of Lake Suwa.

Twenty years are too short a time in which to discuss the climatic variation, hence the real existence of the above period must be proved from the fact of longer duration. By examining the old record of freezing, it was found that apparently the periodic variations of nearly seven and nearly four years are not permanent. Six or seven years variation took place in the intervals of $1445-$ I 472 , I 48 I-I 504, I 5 I6-I53I, I 570-I 588, I642-I669, I673-I $720-1765$, $1805-1825$ and $1838-1858$. But it was obscure during the other years. The variation with a three or four years period was quite remarkable, but many times it was interrupted by sudden short periodic variations with greater amplitude, and it is difficult to decide, whether the reappeared variation of the same type, is the continuation of the former phase or not.

Suppose a case of oscillation in which the phase is not continuous, only the period is kept approximately. Such a case may occur, when a vibrating system has nearly a constant proper period and is excited by spasmodic agitations.

1 R. Spitaler investigated the relation between atmospheric vibration and latitude variation. Petermanns Geographische Mitteilungen Ergänzungshefte.

2 Bigelow: Atmospheric circulation and radiation p. 337. 
A new agitation will commence a new phase of oscillation, and if its amplitude is great, it will be enough to disturb the old weak phase. For the sake of convenience such a type of variation may be called »temporary periodic type».

It is not yet certain that the above variation of ice periods belongs to this type or to the permanent periodic type. If it is temporary, then the ordinary methods of periodigram or method of integration are of no use in order to analyze its periods. So that the following method was adopted as the first step of investigation.

In Fig. I, we can see that the recurring of relatively late freezing occurred once with an interval of two years, twice with one of three years, four years and seven years, but it never occurred with a five and six years interval. We can thus count the number of recurring of relatively late freezing as well as relatively early freezing in that long duration since 1444 for each interval such as $2,3,4 \ldots$ years. If there were no particularity with any individual interval, then the number of recurring, i. e. frequency, must be greater for the two years interval and gradually diminish as the interval increases, and will tend to zero asymptotically as is clear from the theory of probability.

In Fig. 2 are shown two curves of frequency of the late and early freezing of Lake Suwa, for each interval during 429 years, i. e. fron 1444 to 1872 , the ordinate being the number

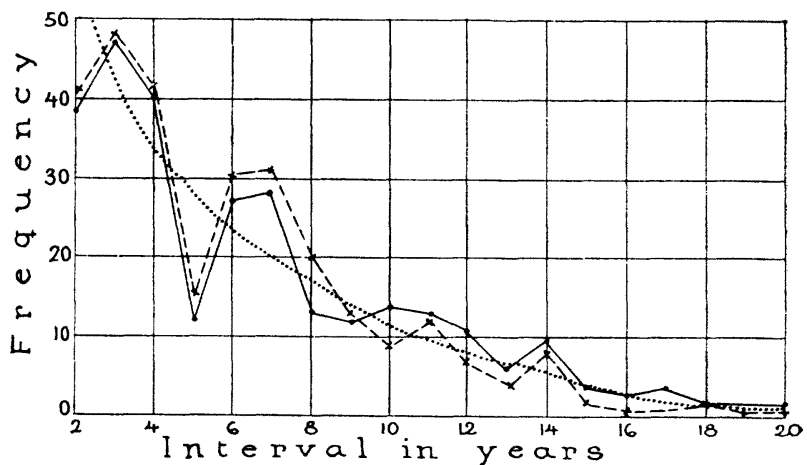

Fig. 2. Frequency for each interval in years of recurring of early and late freezing of Lake Suwa during 429 years.

- Early freezing.
$--\cdots-$ Late
or each interval. of recurring and the abscissa the length of the interval. Generally speaking, these two curves follow the exponential law of distribution of frequency as discussed above, while individuality for each interval is too great to be explained simply as an accidental matter. The frequency is highest for the three years interval, and a little less for the four years one. It sinks low at the five years interval and rises again at the six and seven years interval. Thus further we can also recognize swells at I I and I4 years intervals. Whatever is the true meaning of such a thing, we can see the fact that the climatic tendency to be repeated with a three or four years interval and also with a six or seven years interval was very remarkable during those 429 years in the Suwa district in Japan.

Natural tendency of thought will lead us to connect the results appeared in 
Fig. I and 2. The Bigelow's period of tertiary solar activity is 3.7 years and it must correspond to the greatest frequency at the three and four years intervals in Fig. 2. It is, however, still an open question that which one of the latitude variation and climatic change is the cause of the other. We can also imagine the case that there is some agent which is the cause of both. Anyhow, the fact is that both have the same tendency to repeat the same phase with the period of some six or seven years and their phases nearly coincided during I 896 - I 9 IO.

The swell for the I I years interval in Fig. 2 must be due to the principal phase of the solar activity. In Bigelow's investigation it is also shown that the influence of the tertiary harmonic variation of the solar activity on the earth's atmosphere is far stronger than that of the principal variation.

We shall close this short note now in pointing to the fact that there were spells of very warm winters from $1506-1518$, from $1800-1805$ and also from I $865-1869$. In these winters the lake was not covered with ice.

P. S. According to the investigation by Mr. J. V. Eriksson in the ice periods of Swedish lakes for the period of from I8II to 1916 , there took place rather late freezing of these lakes in the years 1865 , $1867-1869$, which correspond to the years at maximum phase of eleven years period. In 1843,1845 , and 1854 Lake Suwa was not covered with ice, and Sweden experienced also very late freezing of the lakes in these three winters, which correspond also the maximum phase of eleven years variation. The recurring of the same phase after each four years is conspicuous in the smoothed curve $\mathrm{u}_{2}$ of Mr. Eriksson, but there is no trace of six or seven years periods in it. 